The book is based on papers presented at a Nato Advanced Study Institute, organized by the editor during 1965 , and she and her associate editors are to be congratulated on making a valuable addition to laboratory animal literature. JoHN BLEBY

\section{GRASSLAND PRODUCTION}

\section{Methods for the Measurement of the Primary Produc-} tion of Grassland

By C. Milner and R. Elfyn Hughes. (International Biological Programme Handbook, No. 6.) Pp. xii +70 . (Blackwell (Scientific): Oxford and Edinburgh, 1968.) $7 s 6 d$.

THIS is the second publication describing techniques to be used in experiments within the International Biological Programme. This programme is planned to continue only until 1972, and one must question the delay of nearly four years, since its inception, in producing this text. The acknowledgments perhaps make the reason clear. Submission of the text to some twenty authorities may have obviated occasional error; it has also ensured that many parts of the programme have already been planned without the advice it contains.

Grassland is here defined as including grassland, dwarf shrub heaths and arid zone plant communities. The handbook is designed "for those individuals and institutions which require guidance on methods appropriate to these three community types", rather than to standardize "methods used at institutions already pursuing primary production studies".

The first two-thirds of the book describe methods for measuring the primary production of grassland communities. Many of these methods are also appropriate to studies with the dwarf shrub and arid zone communities, of which distinctive features are considered in two shorter sections by C. H. Gimingham and G. R. Miller and by R. O. Slatyer. The terminology is first defined-this is common to all IBP programmes and publications-the main parameter used in these studies, net primary production, being defined as the increase in the biomass of a plant community, but including losses from shedding, decomposition and removal by secondary producers. This is followed by discussion of principles to be considered in selection of the study site, techniques of measurement by harvest and by non-harvest methods, methods of chemical analysis, reporting of results, a summary of advised procedures and a fairly extensive bibliography. Some specific recommendations are made, but in too many instances several references are cited, without a recommendation that one method should be adopted. Thus eight methods of determining root weights are noted; this may present little problem to the trained biologist, experienced in methodology, but the needs of tbe developing biologist--and of standardization within the overall programme-might have been better met had a preforred method been stated. The discussion of principles should, however, assist biologists in deciding the relative importance of measurements on different parts of the ecosystem. The accuracy of measurement of secondary production will generally be less than of primary production, so that it may be more useful to obtain extensive information on primary production at a reasonable level of precision than a small amount of very precise data.

This handbook is too short to include detailed descriptions of techniques. This makes it of much less practical use than Bulletins 45 and 47 of the Commonwealth Bureau of Pastures and Field Crops; these bulletins also include the specific recommendations of techniques which are lacking here. Paradoxically the recommendation that all results should be published in metric units is not adhered to in the figures in part three.

W. F. RAYMOND

\section{SYNTHESIS OF NUCLEIC ACIDS}

\section{Synthetic Procedures in Nucleic Acid Chemistry}

Edited by W. Werner Zorbach and R. Stuart Tipson. Vol. 1: Preparation of Purines, Pyrimidines, Nucleosides, and Nucleotides. Pp. v+570. (Interscience (Wiley): New York and London, January 1968.) 159s. IN recent years, interest in the chemistry and biochemistry of nucleic acids has increased enormously. Many substituted or modified nucleotides have been shown to occur naturally in nucleic acids and the mechanisms of synthesis of nucleic acids are under active investigation. Much remains to be discovered about the biological functions of substituted nucleotides, the nature of the processes leading to the introduction of these substituents in nucleic acids and the effects of such substitutions on the structure of nucleic acids. Analogues of purines and pyrimidines and of their nucleosides and nucleotides are also of considerable value as model compounds which may be used to throw light on the structures of polynucleotides, on the nature of the interactions between one polynucleotide strand and another, and on the interactions between polynucleotides and proteins. It is therefore particularly appropriate that a volume, compiled with the object of gathering together methods for the chemical synthesis of purines and pyrimidines and their analogues and derivatives, should have appeared at this time. Much of this information is scattered very widely throughout the chemical and biochemical literature and is not easily accessible.

The volume is divided into sections dealing with purines and analogues, pyrimidines and analogues, nucleosides, nucleotides and oligonucleotides, and reagents, intermediates and miscellaneous compounds. A wide range of compounds is covered and many different types of synthetic procedure are included. The descriptions of the preparations are clear and concise, and references are given in nearly every instance to the sources of intermediates employed.

The section on nucleotides contains descriptions of the synthesis of a number of nucleotides and some oligonucleotides. The nucleotides selected tend to be of the more esoteric variety and it is unfortunate that there is not a sub-section dealing systematically with the synthesis of the various isomeric ribonucleoside and deoxyribonucleoside monophosphates and polyphosphates. It would also have been useful to include a rather fuller section on the synthesis of specific oligonucleotides, because such compounds are of great interest at present and are likely to be of greater interest in future, particularly to biochemists.

This will be a most useful book to many chemists and biochemists and it is to be hoped that the editors will take steps to remedy, in subsequent volumes in this series, the omissions that have been mentioned.

R. M. S. SMellie

\section{REVISION CHEMISTRY}

\section{Principles of Chemistry}

By Sonia Dunstan. Pp. xii +493 . (Van Nostrand: London and Princeton, NJ, November 1968.) $75 s$.

THIs book represents the fruits of experience gained from lecturing, in the University of Manchester, to a group of undergraduates studying chemistry for one year as an ancillary requirement of honours courses in general science, geology, zoology, botany, geography, psychology, medicine and liberal studies-the students having had little or no previous experience of chemistry. The book does, however, differ from the course in that the latter spent about one-fifth of the available time on organic chemistry, whereas the book contains none explicitly and little or 